\title{
Biometria aplicada ao melhoramento intrapopulacional do maracujazeiro amarelo ${ }^{1}$
}

\author{
Biometrics applied to intra-population improvement of the yellow passion fruit
}

\author{
Marcelo Geraldo de Morais Silva², Alexandre Pio Viana ${ }^{3 *}$, Antonio Teixeira do Amaral Júnior ${ }^{3}$, Leandro Simões \\ Azeredo Gonçalves ${ }^{3}$ e Ronaldo Viana dos Reis ${ }^{4}$
}

\begin{abstract}
RESUMO - Objetivou-se estimar parâmetros genéticos associados a onze características agronômicas de uma população de maracujazeiro amarelo sob seleção recorrente, utilizando-se 140 progênies de irmãos completos do segundo ciclo, com plantio em outubro de 2007, em delineamento látice quadrado simples e parcelas constituídas de três plantas. Os quadrados médios das características revelaram significância pelo teste $\mathrm{F}$ para o efeito de progênies, indicando que existe variabilidade genética a ser explorada nos próximos ciclos. As estimativas dos coeficientes de herdabilidade variaram de 19,54 a 71,38\%. As médias das principais características de importância agronômica da população avaliadas foram superiores às das testemunhas, ratificando o potencial da população em gerar população superior com o acúmulo de alelos favoráveis nos sucessivos processos seletivos. As estimativas dos parâmetros genéticos e fenotípicos das principais características de importância econômica revelam a possibilidade de sucesso com a seleção de progênies superiores de maracujazeiro amarelo no intento de registro e proteção de nova cultivar.
\end{abstract}

Palavras-chave: Passiflora edulis Sims. Ganhos por seleção. Seleção intrapopulacional. Nova cultivar.

\begin{abstract}
The objective of the study was to estimate genetic parameters associated with eleven agronomic traits of a population of yellow passion fruit under recurrent selection, using 140 full-sibling progenies from the second cycle, planted in October 2007 in a simple square lattice design and in plots consisting of three plants. The mean squares of their features revealed F-test significance for the effect of progeny, indicating that there is genetic variability to be explored in the next cycles. Estimates of heritability coefficients ranged from 19.54 to $71.38 \%$. The averages of the main characteristics of agronomic importance in the studied population were higher than those of the controls, confirming the potential of the population to generate a superior population with the accumulation of favorable alleles in successive processes of selection. Estimates of genetic and phenotypic parameters of the main characteristics of economic importance reveal the possibility of success in the selection of superior progenies of yellow passion fruit, with the aim of registration and protection of a new cultivar.
\end{abstract}

Key words: Passiflora edulis Sims. Selection gains. Intra-population selection. New cultivar.

\footnotetext{
*Autor para correspondência

${ }^{1}$ Recebido para publicação em: 27/04/2010; aprovado em: 21/11/2011

Parte da Tese de Doutorado do primeiro autor

${ }^{2}$ Instituto Federal do Norte de Minas Gerais, Km 06, Januária-MG, Brasil, 39.480-000, mcoro2003@yahoo.com.br

${ }^{3}$ Universidade Estadual do Norte Fluminense Darcy Ribeiro/UENF, Av. Alberto Lamego 2000, Campos dos Goytacazes-RJ, Brasil, 28.013-602, pirapora@uenf.br, amaraljr@uenf.br, lsagrural@yahoo.com.br

${ }^{4}$ Universidade Federal de Viçosa/UFV, Viçosa-MG, Brasil, ronasviana@yahoo.com.br
} 


\section{INTRODUÇÃO}

Registros do Agrianual (2010) estimam o Brasil como o maior produtor mundial de maracujá amarelo (Passiflora edulis Sims), sendo produzido no país cerca de 615 mil toneladas. Some-se a isso o rápido retorno econômico no cultivo da espécie, com a receita distribuída em vários meses do ano durante a safra, permitindo não apenas o aumento da rentabilidade de cultivo por unidade de área, mas também distribuição mais equitativa dos lucros auferidos durante o ano.

Apesar dessas vantagens, a produtividade nacional é baixa, com valor aproximado de $13,9 \mathrm{t} \mathrm{ha}^{-1}$, devido, principalmente, ao baixo emprego de tecnologia de produção e carência de populações geneticamente melhoradas (AGRIANUAL, 2010; MELETTI; MAIA, 1999). Dentre as opções para melhoria desse cenário, a de maior impacto é a obtenção de cultivares mais produtivas e resistentes a pragas e doenças.

Existem diversos métodos de melhoramento aplicáveis ao maracujuzeiro, entre esses, a seleção recorrente (GONÇALVES et al., 2008; GONÇALVES et al., 2009; MELETTI et al., 2000; SILVA et al., 2009). Neste método busca-se a melhor performance das populações de forma continua e progressiva por meio do aumento das frequências dos alelos favoráveis dos caracteres sob seleção, mantendo a variabilidade genética em níveis adequados para permitir ganhos genéticos nos ciclos subsequentes (HALLAUER, 1985; HULL, 1945; SOUZA JÚNIOR, 2001).

Nesse contexto, a estimação de parâmetros genéticos na unidade de seleção, tais como herdabilidade, variância genotípica, coeficientes de variação genotípico e experimental e índice de variação, constitui-se na inferência de inequívoca importância para obtenção de informações sobre a natureza da ação dos genes envolvidos no controle dos caracteres. Além disso, avalia a eficiência de diferentes estratégias de melhoramento para obtenção de ganhos genéticos e manutenção de uma base genética adequada (CRUZ; CARNEIRO, 2003; HALLAUER; MIRANDA FILHO, 1988; VENCOVSKY; BARRIGA, 1992; VIANA et al., 2004).

Diversos trabalhos têm sido desenvolvidos com o objetivo de estimar parâmetros genéticos e fenotípicos em populações de várias espécies vegetais (BEZERRA NETO et al., 2006; CAMARGO, 1998; COELHO et al., 2002; FARIAS NETO et al., 2008; SOUZA et al., 2000). Entretanto, para a cultura do maracujazeiro são poucas as informações disponíveis (GONÇALVES et al., 2009; OLIVEIRA et al., 2008; SILVA et al., 2009).

Assim, julgou-se oportuno o desenvolvimento desse trabalho que tencionou avaliar progênies de irmãos- completos do segundo ciclo de seleção recorrente e estimar parâmetros genéticos associados a onze características agronômicas de maracujazeiro amarelo (P. edulis Sims).

\section{MATERIAL E MÉTODOS}

Foram obtidas 140 progênies de irmãos-completos por meio de cruzamentos dirigidos da população melhorada denominada MA (SILVA et al., 2009) de maracujazeiro amarelo que, juntamente com quatro testemunhas foram avaliadas em outubro de 2007 na estação experimental da Escola Agrícola Antônio Sarlo, no município de Campos dos Goytacazes, região Norte do Estado do Rio de Janeiro (latitude: $21^{\circ} 45^{\prime} \mathrm{S}$, longitude $41^{\circ} 20^{\prime} \mathrm{W}$ e altitude: $11 \mathrm{~m}$ acima do nível do mar).

O delineamento estatístico adotado foi o látice quadrado, com duas repetições e três plantas por parcelas. O tamanho total da parcela foi de $6,0 \mathrm{~m}$, com espaçamento entre plantas de 2,0 m. O sistema de condução foi o de espaldeira vertical, com mourões de eucalipto tratado de $2,5 \mathrm{~m}$ de altura espaçados de 4 metros e com um fio de arame número 12 a $1,80 \mathrm{~m}$ do solo. A distância entre linhas de plantio foi de $3,5 \mathrm{~m}$ e todos os tratos culturais foram realizados quando necessários, conforme as recomendações para a cultura do maracujazeiro (MANICA, 1981).

As características avaliadas foram: número de dias para o florescimento (DF); peso médio dos frutos, em gramas (PF); comprimento médio dos frutos, em mm (CF); largura média dos frutos, em mm (LF); espessura média de casca, em mm (EC); teor de sólidos solúveis totais (SS); coloração da polpa (CP); média percentual de polpa (PP); número total de frutos (NF); produção total, em tha ${ }^{-1}(\mathrm{PT})$; e peso médio de frutos, em $\mathrm{g}$ (PMF).

A análise de variância para cada característica avaliada foi realizada adotando o seguinte modelo estatístico (Equação 1):

$Y_{i j k}=\mu+\mathrm{r}_{\mathrm{j}}+\mathrm{b}_{\mathrm{k}(j)}+\mathrm{g}_{1}+\varepsilon_{\mathrm{ijk}}$

em que: $Y_{i j k}$ é a observação referente a i-ésima progênie no k-ésimo bloco, dentro da j-ésima repetição; $\mu$ é a média geral; $r_{j}$ é o efeito da j-ésima repetição; $b_{k(j)}$ é o efeito do k-ésimo bloco, na j-ésima repetição; $g_{i}$ é o efeito da i-ésima progênie e $\varepsilon_{i j k}$ é o erro experimental $\sim \mathrm{NID}\left(0, \sigma^{2}\right)$. Todas as fontes de variação foram consideradas aleatórias, exceto a média.

Com base nas estimativas dos quadratórios médios, foram estimados os seguintes componentes de variância:

a) variância genotípica entre médias de progênies (Eq. 2): 


$$
\hat{\sigma}^{2}=\frac{Q M G-Q M E}{r}
$$

em que: $\mathrm{QMG}=$ quadrado médio de progênies; $\mathrm{QME}=$ quadrado médio do erro efetivo; e $\mathrm{r}=$ número de repetições;

b) variância fenotípica entre médias de progênies (Equação 3):

$\hat{\sigma}_{f}^{2}=\frac{Q M G}{r}$

c) coeficiente de herdabilidade (Equação 4):

$h^{2}=\frac{\hat{\sigma}_{g}^{2}}{\wedge_{f}^{2}}=\frac{Q M G-Q M E}{Q M G}$

d) correlação intraclasse (Equação 5):

$C \hat{V}_{g}=\frac{\sqrt{\sigma_{g}^{2}}}{m} \times 100$

e) coeficiente de variação genético (Equação 6):

$C \hat{V}_{e}=\frac{\sqrt{Q M E}}{m} \times 100$

em que: $m=$ média geral.

f) coeficiente de variação experimental (Equação 7):

$C \hat{V}_{e}=\frac{\sqrt{Q M E}}{m} \times 100$ g) índice de Variação (Equação 8)

$\hat{I}_{v}=\frac{C V_{g}}{C V_{e}}$

As médias das progênies para as características estudadas, significativas pelo teste $\mathrm{F}$, foram agrupadas pelo procedimento proposto por Scott-Knott (1974) no nível de $5 \%$ de probabilidade, utilizando-se o programa computacional Genes (CRUZ, 2006).

\section{RESULTADOS E DISCUSSÃO}

A existência da variabilidade entre indivíduos da unidade de seleção foi constatada pela significância, em P $<0,05$ pelo teste $F$ para as características avaliadas, exceto cor da polpa (CP) (Tabela 1). A precisão ou qualidade experimental, avaliada estatisticamente por meio do coeficiente de variação experimental $(\mathrm{CVe})$, revelou valores de 4,13 a $28,39 \%$ (Tabela 1), sendo estes limites correspondentes à largura de fruto (LF) e produção total (PT), respectivamente. Moraes et al. (2005) avaliando uma população $\mathrm{F}_{1}$ com 100 genótipos, oriunda do cruzamento entre IAPAR-06 e IAPAR-123, obtiveram CVe de 23,80\% para PT, o que corrobora os resultados obtidos. O segundo maior valor obtido foi $28,36 \%$ para a característica número de frutos (NF). Para esta característica, Silva et al. (2009), avaliando 26 progênies de meios-irmãos proveniente da recombinação de genótipos selecionados do primeiro ciclo de seleção via delineamento I, encontraram CVe de 71,91\%. Moraes et al. (2005) obtiveram estimativa de CVe de $11,80 \%$, contudo, a análise foi feita com dados transformados.

Tabela 1 - Resumo da análise de variância para onze características agronômicas e do fruto de maracujazeiro amarelo

\begin{tabular}{|c|c|c|c|c|c|c|c|c|c|c|c|c|}
\hline \multirow{2}{*}{$\mathrm{FV}$} & \multirow{2}{*}{ GL } & \multicolumn{11}{|c|}{ Quadrados Médios ${ }^{(1)}$} \\
\hline & & DF & $\mathrm{PF}$ & $\mathrm{CF}$ & LF & $\mathrm{NF}$ & PT & PMF & EC & SS & $\mathrm{CP}$ & PP \\
\hline Repetições & 1 & 1582,0 & 0,90 & 26,05 & 14,69 & 21372,7 & 204,57 & 6,66 & 3,62 & 1,20 & 0,31 & 142,66 \\
\hline Bloco/Rep. & 22 & 506,25 & 265,84 & 16,16 & 5,93 & 2064,2 & 15,50 & 110,28 & 0,42 & 1,19 & 0,16 & 24,82 \\
\hline Progênies & 143 & $293,75^{* * *}$ & $656,51^{* *}$ & $40,66^{* *}$ & $16,90^{* *}$ & 3578,0 *** & $29,93^{* *}$ & $474,03 * *$ & $1,01 * *$ & $1,40 * *$ & $0,34^{\mathrm{ns}}$ & $47,16^{* *}$ \\
\hline Erro Efetivo & 121 & 191,75 & 332,21 & 17,48 & 9,35 & 2175,7 & 21,54 & 135,65 & 0,51 & 0,76 & 0,27 & 21,65 \\
\hline Ef. Látice & - & 117,47 & 96,92 & 98,83 & 94,37 & 99,21 & 95,68 & 97,12 & 97,36 & 103,78 & 93,61 & 100,38 \\
\hline $\mathrm{CV}$ & - & 11,66 & 11,30 & 5,16 & 4,13 & 28,36 & 28,39 & 8,25 & 11,31 & 7,17 & 12,33 & 11,64 \\
\hline Média & - & 118,66 & 161,18 & 80,91 & 73,86 & 164,4 & 16,34 & 141,15 & 6,30 & 12,18 & 4,25 & 39,97 \\
\hline LI & - & 94,12 & 116,09 & 67,55 & 65,31 & 58 & 5,98 & 102,88 & 4,59 & 9,68 & 3,00 & 27,40 \\
\hline LS & - & 149,92 & 218,2 & 91,23 & 80,65 & 266,0 & 29,2 & 182,91 & 8,06 & 14,55 & 5,25 & 53,88 \\
\hline Média test. & & 113,88 & 144,53 & 81,62 & 70,48 & 141,88 & 12,57 & 130,95 & 5,19 & 12,09 & 4,50 & 43,50 \\
\hline
\end{tabular}

${ }^{(1)} \mathrm{DF}=$ número de dias para o florescimento, $\mathrm{PF}=$ peso de fruto, $\mathrm{CF}=$ comprimento de fruto, $\mathrm{LF}=$ largura de fruto, $\mathrm{NF}=$ número total de frutos, $\mathrm{PT}=$ produção total em ton/ha, $\mathrm{PMF}=$ peso médio de fruto, $\mathrm{EC}=$ espessura de casca, $\mathrm{SS}=$ teor de sólidos solúveis totais, $\mathrm{CP}=$ cor da polpa, $\mathrm{PP}=$ peso da polpa. $* *, *$ e ns Significativo a $1 \%$ e $5 \%$ de probabilidade e não significativo, respectivamente, pelo teste $\mathrm{F}$ 
Vale ressaltar que a elevada magnitude dos valores de CVe para PT e NF não indicam que houve imprecisão na condução do experimento ou na aferição dos dados, mas sim que as características em questão são controladas por vários genes e, por isso, estão sob elevada influência ambiental. Para as demais características, as estimativas dos CVe foram de baixa magnitude e têm consonância a demais trabalhos realizados com a cultura do maracujazeiro (GONÇALVES et al., 2007; MORAES et al., 2005; OLIVEIRA et al., 2008; SILVA et al., 2009; VIANA et al., 2004).

Na Tabela 1, também há as estimativas das médias da população original, do limite inferior (LI) e superior (LS) das médias das progênies e das médias das testemunhas utilizadas no ensaio. Daros et al. (2004), avaliando 222 progênies $S_{1}$ de milho pipoca, concluíram que o LS não é um teto, mas um valor a ser acrescido pelo ganho de seleção, devendo ser entendido como um valor máximo detectado em determinado ciclo, que poderá ser inferior ao máximo para o ciclo seguinte e, assim, sucessivamente, com o aumento na frequência de alelos favoráveis na população.

Pelos resultados contidos na Tabela 1 , constata-se que, para as características consideradas principais, NFe PT, houve grande amplitude entre os limites estabelecidos, representando, respectivamente, 358,60 e 388,30\% de incremento do LI ao LS, o que corrobora a elevada variabilidade genética presente na população de maracujazeiro amarelo e constitui uma perspectiva de condição essencial para a obtenção de progênies superiores via seleção. Foram observados incrementos da ordem de $62,70 \% ; 87,90 \% ; 35,10 \% ; 23,40 \%, 77,80 \%$; $56,90 \% ; 50,30 \% ; 75,00 \%$ e $96,60 \%$ para as características DF, PF, CF, LF, PMF, EC, SS, CPe PP, respectivamente, denotando novamente a presença de ampla variabilidade genética entre as progênies de irmãos-completos da unidade de seleção, o que permite inferir sobre a perspectiva de sucesso nos ganhos seletivos para os sucessivos ciclos de seleção recorrente.

Outra observação pertinente refere-se ao potencial da população em gerar indivíduos superiores pela seleção. Quando se compara a média geral da população com a média geral das testemunhas, nota-se que aquela foi maior para a maioria das características avaliadas. Porém, é evidente que estes genótipos superiores apresentam uma adaptação regional (interação favorável) e as testemunhas, por outro lado, não apresentaram tal adaptação, sendo influenciadas pelo ambiente. Por conseguinte, ganhos expressivos podem ser almejados nos próximos ciclos de seleção, já que há a conjunção do binômio ideal, qual seja, média alta e elevada diversidade genética entre os indivíduos componentes da unidade de seleção (RAMALHO et al., 2001).

É concebido que a herdabilidade é a proporção da variância fenotípica que é de origem genética, ou seja, expressa o grau de correlação entre o fenótipo e o genótipo. Dessa forma, ela infere a confiabilidade de valor fenotípico como indicador do verdadeiro valor genotípico (FALCONER, 1981). Dessa maneira, pode-se saber se as diferenças detectadas são de natureza genética e se a seleção tenderá a proporcionar ganhos em programas de melhoramento genético.

As estimativas dos coeficientes de herdabilidade variaram de 19,54 a 71,38\% (Tabela 2). A característica cor de polpa (CP) foi a única em que os efeitos de progênies foram não significativos, o que resultou no menor valor de herdabilidade do presente trabalho. Por outro lado, a maior estimativa foi expressa por peso médio de fruto (PMF). A seleção de progênies com maior PMFé interessante, pois um material genético com esta característica pode representar ganhos a mais para os produtores, já que normalmente o peso tem correlação direta e positiva com tamanho de fruto e, com isso, podem atingir preços mais atrativos se destinados ao mercado in natura (MELETTI et al., 2000).

As duas características mais importantes avaliadas, número de frutos (NF) e produção total (PT), exibiram baixas estimativas de herdabilidade, com valores respectivos de 39,19 e $28,04 \%$. No entanto, não se pode concluir que os ganhos genéticos com a seleção serão menores, pois estimativas de valores de alta magnitude de herdabilidade podem ocorrer para características deínfimos valores de variância genética, desde que a interferência ambiental na característica seja também de reduzida magnitude. De fato, estas características possivelmente foram as mais influenciadas pelas variações ambientes, tendo revelado os maiores coeficientes de variação.

Moraes et al. (2005) obtiveram altos valores de herdabilidades para NF e PT (82,20 e 83,00\%, respectivamente). Entretanto, sabe-se que a herdabilidade não é uma estimativa imutável; embora seja uma das mais importantes informações da genética de populações, a herdabilidade é tão somente uma perspectiva e não uma razão absoluta.

As estimativas de herdabilidade podem variar de acordo com a característica avaliada, o método de estimação, a diversidade na população, a unidade experimental considerada, o tamanho da amostra avaliada, o nível de endogamia da população, o número e tipos de ambientes considerados e a precisão na condução do experimento e na coleta de dados (BORÉM; MIRANDA, 2005; HALLAUER; MIRANDA FILHO, 1988; VENCOVSKY; BARRIGA, 1992). Consequentemente, estas estimativas não devem ser extrapoladas para outras populações.

Para NF, Linhales (2007), Oliveira et al. (2008) e Silva et al. (2009), trabalhando com maracujazeiro-amarelo, obtiveram estimativas de herdabilidades de 33,00\%; $54,00 \%$ e $36,90 \%$, nessa ordem, com certa concordância com os resultados obtidos no presente trabalho. Por sua vez, Viana et al. (2004), em avaliação de 20 genótipos 
Tabela 2 - Estimativas de parâmetros genéticos relacionados a 11 características avaliadas em 140 progênies de irmãos completos de maracujazeiro amarelo

\begin{tabular}{lrrrrrrrr}
\hline & \multicolumn{7}{c}{ Parâmetros Genéticos ${ }^{(2)}$} \\
\cline { 2 - 8 } Características $^{(1)}$ & \multicolumn{1}{c}{$\sigma_{g}{ }^{2}$} & \multicolumn{1}{c}{$\sigma_{f}{ }^{2}$} & \multicolumn{1}{c}{$\sigma_{e}{ }^{2}$} & \multicolumn{1}{c}{$h^{2}$} & \multicolumn{1}{c}{$C I$} & $C V_{e}$ & $C V_{g}$ & $\hat{I}_{v}$ \\
\hline DF & 50,99 & 146,87 & 95,87 & 34,72 & 0,2100 & 11,66 & 6,02 & 0,52 \\
PF & 162,15 & 328,25 & 166,10 & 49,39 & 0,3280 & 11,30 & 7,90 & 0,69 \\
CF & 11,58 & 20,33 & 8,74 & 56,99 & 0,3985 & 5,16 & 4,20 & 0,81 \\
LF & 3,77 & 8,45 & 4,67 & 44,69 & 0,2877 & 4,13 & 2,63 & 0,63 \\
NF & 701,14 & 1789,00 & 1087,8 & 39,19 & 0,2437 & 28,36 & 16,10 & 0,56 \\
PT & 4,19 & 14,96 & 10,77 & 28,04 & 0,1631 & 28,39 & 12,53 & 0,44 \\
PMF & 169,19 & 237,00 & 67,82 & 71,38 & 0,5550 & 8,25 & 9,21 & 1,11 \\
EC & 0,24 & 0,50 & 0,30 & 49,55 & 0,3293 & 11,31 & 7,92 & 0,70 \\
SS & 0,31 & 0,70 & 0,38 & 45,93 & 0,2932 & 7,17 & 4,62 & 0,64 \\
CP & 0,03 & 0,17 & 0,13 & 19,54 & 0,1083 & 12,33 & 4,29 & 0,34 \\
PP & 12,75 & 23,58 & 10,82 & 54,09 & 0,3707 & 11,64 & 8,93 & 0,76 \\
\hline
\end{tabular}

(1) $\mathrm{DF}=$ número de dias para o florescimento, $\mathrm{PF}=$ peso de fruto, $\mathrm{CF}=$ comprimento de fruto, $\mathrm{LF}=$ largura de fruto, $\mathrm{NF}=$ número total de frutos, $\mathrm{PT}=$ produção total $\mathrm{em} \mathrm{tha}^{-1}, \mathrm{PMF}=$ peso médio de fruto, $\mathrm{EC}=$ espesşura de casca, $\mathrm{SS}=$ teor de sólidos solúveis totais, $\mathrm{CP}=$ cor da polpa, $\mathrm{PP}=$ peso da polpa. (2) $\sigma_{g}^{2}=$ variância genotípica, $\sigma_{g}^{2}=$ variância fenotípica, $\sigma_{g}^{2}=$ variância residual, $h^{2}=$ herdabilidade, $C I=$ correlação intraclasse, $C V_{e}=$ coeficiente de variação experimental, $C V_{g}=$ côeficiente de variação genético e $\hat{I}_{v}=$ índice de variação

provenientes de três municípios do Norte e Noroeste do Estado do Rio de Janeiro (Campos dos Goytacazes, São Francisco do Itabapoana e Itaperuna), obtiveram estimativa de herdabilidade de 92,10\%. Entretanto, cabe destacar que os autores trabalharam com seleção clonal.

De todo modo, para a maioria das características avaliadas no trabalho aqui realizado, os resultados das estimativas de herdabilidade revelaram valores abaixo de 50\%. Para peso de fruto (PF), por exemplo, a magnitude foi $49,39 \%$. Em outros trabalhos, essas estimativas variaram de 56,10 a 70\% (GONÇALVES et al., 2007; LINHALES, 2007; MORAES et al., 2005; OLIVEIRA et al., 2008; SILVA et al., 2009; VIANA et al., 2004). Para comprimento médio de fruto (CF), largura média de fruto (LF) e número médio de dias para o florescimento (DF), as estimativas foram de 56,99; 44,69 e 34,72\%, respectivamente, denotando tratar-se de características oligogênicas.

Para características de interesse ao processamento industrial como espessura média de casca (EC), teor de sólidos solúveis (SS), cor da polpa (CP) e média percentual da polpa (PP), as estimativas de herdabilidades foram de 49,55; 45,93; 19,54 e 54,09\%, respectivamente. Para CP, Linhales (2007) obteve estimativa de 42,00\%, sendo este o único trabalho encontrado na literatura que relata a avaliação desta característica. Em relação a SS, Viana et al. (2004) obtiveram estimativa de herdabilidade nula, enquanto Moraes et al. (2005), obtiveram magnitude de $80 \%$, evidenciando uma maior discrepância nas estimativas para esta característica. Para PP, alguns trabalhos revelaram estimativas acima de 50\% (LINHALES, 2007; MORAES et al., 2005), já em outros, estas foram baixas, 28\%, (OLIVEIRA et al., 2008) e até mesmo nulas (VIANA et al., 2004).

Estimativas do coeficiente de variação genético $\left(\mathrm{CV}_{\mathrm{g}}\right)$ permitem ao melhorista ter uma percepção da grandeza relativa das mudanças que podem ser obtidas por meio de seleção, ao longo de um programa de melhoramento, já que se trata de um parâmetro, cuja estimativa é diretamente proporcional à variância genética. De acordo com a Tabela 2, as características que expressaram os maiores valores de $\mathrm{CV}_{\mathrm{g}}$ foram $\mathrm{NF}$ e PT, indicando boas chances de sucesso na seleção para número e peso total de frutos. Moraes et al. (2005) também obtiveram valores elevados de $\mathrm{CV}_{\mathrm{g}}$ para as características NF e PT, com magnitudes respectivas de 15 e $29,5 \%$. Viana et al. (2004) obtiveram estimativa de 62,18\% para NF. Para as demais características, os valores de $\mathrm{CV}_{\mathrm{g}}$ variaram de 2,63 a $9,21 \%$.

Outro parâmetro que quando estimado concomitantemente com o $\mathrm{CV}_{\mathrm{g}}$ pode auxiliar na tomada de decisão do processo seletivo é o índice de variação (Iv). Por não ser influenciado pela média e por traduzir a relação entre $\mathrm{CV}_{\mathrm{g}}$ e $\mathrm{CV}_{\mathrm{e}}$, permitindo supor sobre a eficiência de programas de melhoramento na obtenção de ganhos seletivos desejáveis. Não por acaso Vencovsky, (1987) 
propalou que o estimador Iv é utilizado para determinar as chances de sucesso na seleção, no que dependerá de sua magnitude, principalmente para as situações em que for igual ou superior à unidade.

A característica PMF expressou estimativa de Iv superior à unidade, revelando maior influência da variação genética na expressão genotípica, ao mesmo lapso que indica que métodos simples de melhoramento seriam suficientes para a obtenção de ganhos satisfatórios (Tabela 2). Para as características DF, PF, CF, LF, NF, EC, SS e PP, com estimativas moderadas de Iv, métodos de seleção mais complexos são requeridos para proporcionar ganhos genéticos aceitáveis. Por outro lado, CPe PT foram as únicas características com valores inferiores a 0,5. Nesse caso, fica evidenciada a maior proporção de variação ambiental, que é uma situação menos favorável ao melhoramento, mas que pode ser contornado com a utilização de métodos de melhoramento ainda mais elaborados.

A análise das médias fenotípicas foi realizada utilizando-se o procedimento de Scott-Knott (1974), no nível de 5\% de probabilidade. Segundo Ramalho et al. (2000), este procedimento de comparação de médias contorna o problema da ambiguidade nos resultados e apresenta alta capacidade de identificar todas as reais diferenças entre os materiais genéticos testados.

Como esperado, a única característica que não apresentou formação de grupos foi $\mathrm{CP}$, já que diferenças significativas entre as progênies para este caráter não foi detectado pelo teste F. Para peso médio de frutos (PMF) houve a formação de três grupos e para as demais características houve formação de dois grupos. Para PMF, o grupo com média superior $(152,6)$ superou o segundo $(133,8)$ em $14,06 \%$ e o terceiro $(116,9)$ em $30,43 \%$, reforçando, assim, a alta variabilidade existente para essa característica. As características DF e EC, para as quais se tem o interesse em diminuir as estimativas das médias, apresentaram no grupo de menor média uma redução de 15,26 e $16,54 \%$ para com o grupo de maior média, respectivamente. Para PF, o grupo com média superior $(182,6)$ superou o outro grupo $(152,1)$ em $20,05 \%$. Para CF, o grupo com média superior $(84,4)$ superou o outro $(77,32)$ em $9,19 \%$. Para LF, o grupo com média superior $(76,7)$ superou o outro $(71,9)$ em $6,69 \%$. Para SS e PP os grupos com médias superiores suplantaram os outros grupos em 11,60 e 21,65\%, respectivamente. Porém, o destaque foram as características NF e PT, em que os grupos com médias superiores foram, respectivamente, 49,08 e 46,80\% maiores na comparação com os grupos de médias inferiores, ratificando a ampla variabilidade genética das progênies avaliadas para essas características.

\section{CONCLUSÃO}

A existência de variabilidade genética disponível na população, associada a uma alta média, bem como as estimativas dos parâmetros genéticos e fenotípicos revelaram a possibilidade de sucesso com a seleção de progênies superiores de maracujazeiro amarelo.

\section{AGRADECIMENTOS}

À FAPERJ pelo apoio financeiro na condução do experimento e pela bolsa de doutorado do primeiro autor.

\section{REFERÊNCIAS}

ANUÁRIO Estatístico da Agricultura Brasileira (AGRIANUAL). São Paulo: FNP, 2010.520 p.

BEZERRA NETO, F. V. et al. Análise biométrica de linhagens de abóbora. Horticultura Brasileira, v. 24, n. 03, p. 378-380, 2006.

BORÉM, A.; MIRANDA, G. V. Melhoramento de plantas. Viçosa: UFV, 2005, $525 \mathrm{p}$.

CAMARGO, C. E. O. Estimativas de herdabilidades e correlações entre produção de grãos e seus componentes para cruzamentos biparentais de trigo. Scientia Agricola, v. 55, n. 01, p. 111-118, 1998.

COELHO, A. D. F. et al. Herdabilidades e correlações da produção do feijão e dos seus componentes primários, nas épocas de cultivo da primavera-verão e do verão-outono. Ciência Rural, v. 32 , n. 02 , p. 211-216, 2002.

CRUZ, C. D. Programa genes: biometria. Viçosa: UFV, 2006. 382 p.

CRUZ, C. D.; CARNEIRO, P. C. S. Modelos biométricos aplicados ao melhoramento genético. Viçosa: UFV, 2003. , 585 p. v. 2.

DAROS, M. et al. Recurrent selection in inbred popcorn families. Scientia Agricola, v. 61, n. 06, p. 609-614, 2004.

FALCONER, D. S. Introdução à genética quantitativa. Viçosa: UFV, 1981. 279 p.

FARIAS NETO, J. T. et al. Estimativas de parâmetros genéticos e ganhos de seleção em progênies de polinização aberta de açaizeiro. Revista Brasileira de Fruticultura, v. 30, n. 04, p. 1051-1056, 2008.

GONÇALVES, G. M. et al. Seleção e herdabilidade na predição de ganhos genéticos em maracujá-amarelo. Pesquisa Agropecuária Brasileira, v. 42, n. 02, p. 235-240, 2007.

GONÇALVES, G. M. et al. Correlações fenotípicas e genéticoaditivas em maracujá-amarelo pelo delineamento I. Ciência e Agrotecnologia, v. 32, n. 05, p. 1413-1418, 2008.

GONÇALVES, G. M. et al. Genetic parameter estimates in yellow passion fruit based on design I. Brazilian Archives of Biology and Technology, v. 52, n. 03, p. 523-530, 2009. 
HALLAUER, A. R. Compedium of recurrent selection methods and their application. Review in Plant Science, v. 03, n. 01, p. 1-34, 1985.

HALLAUER, A. R.; MIRANDA FILHO, J. B. Quantitative genetics in maize breeding. Ames: Iowa State University Press, 1988. $468 \mathrm{p}$.

HULL, F. H. Recurrent selection and specific combining ability in corn. Journal American Society of Agronomy, v. 37, p. $134-145,1945$.

LINHALES, H. Seleção em famílias de irmãos completos de maracujazeiro amarelo (Passiflora edulis Sims f. flavicarpa Deg.) no segundo ano de produção. 2007. 72 f. Dissertação (Mestrado em Fitotecnia) - Universidade Federal de Viçosa, Viçosa.

MANICA, I. Fruticultura: 1. Maracujá. São Paulo: Ceres, 1981. $151 \mathrm{p}$.

MELETTI, L. M. M.; MAIA, M. L. Maracujá: produção e comercialização. Campinas: Instituto Agronômico, 1999. 62 p. (Boletim Técnico, 181).

MELETTI, L. M. M. et al. Melhoramento do maracujazeiroamarelo: obtenção do composto IAC-27. Scientia Agricola, v. 56, n. 03, p. 491-498, 2000.

MORAES, M. C. de. et al. Genetic and phenotypic parameter estimates for yield and fruit quality traits from a single wide cross in yellow passion fruit. HortScience, v. 40, n. 07, p. 1978-1981, 2005.

OLIVEIRA, E. J. et al. Seleção em progênies de maracujazeiroamarelo com base em índices multivariados. Pesquisa Agropecuária Brasileira, v. 43, n. 11, p. 1543-1549, 2008.
RAMALHO, M. A. P. et al. Experimentação em genética e melhoramento de plantas. Lavras: UFLA, 2000. 326 p.

RAMALHO, M. A. P. et al. Melhoramento de espécies autógamas. In: NASS, L. L.; VALOIS, A. C. C; MELO, I. S. de; VALADARESINGLIS, M. C. (Org.). Recursos genéticos e melhoramento de plantas. Rondonópolis: Fundação MT, 2001, p. 201-230. v. 1,

SCOTT, A. J.; KNOTT, M. A cluster analysis method for grouping means in the analysis of variance. Biometrics, v. 30, n. 03, p. 507-512, 1974.

SILVA, M. G. M. et al. Seleção recorrente intrapopulacional no maracujazeiro amarelo: Alternativa de capitalização de ganhos genéticos. Ciência e Agrotecnologia, v. 33, n. 01, p. 170-176, 2009.

SOUZA, E. A. et al. Alternativas experimentais na avaliação de famílias em programas de melhoramento genético do feijoeiro. Pesquisa Agropecuária Brasileira, v. 35, n. 09, p. 1765-1771, 2000.

SOUZA JÚNIOR, C. L. de. Melhoramento de espécies alógamas. In: NASS, L. L.; VALOIS, A. C. C; MELO, I. S. de; VALADARESINGLIS, M. C. (Org.). Recursos genéticos e melhoramento de plantas. Rondonópolis: Fundação MT, 2001, p. 159-199. v. 01.

VENCOVSKY, R. Herança quantitativa. In: PATERNIANI, E., VIÉGAS, G. P., (Ed). Melhoramento e produção do milho. Campinas: Fundação Cargill, 1987. cap.5, p. 137-214.

VENCOVSKY, R.; BARRIGA, P. Genética biométrica no fitomelhoramento. Ribeirão Preto: Sociedade Brasileira de Genética, 1992. 486 p.

VIANA, A. P. et al. Parâmetros genéticos em populações de maracujazeiro amarelo. Revista Ceres, v. 51, n. 297, p. 541-555, 2004. 